\title{
PRODUÇÃO CIENTÍFICA NO JUDÔ: DA ACADEMIA ÀS ACADEMIAS
}

Luiz Henrique da Silva

Antônio Carlos Tavares Junior

Alexandre Janotta Drigo

\section{Resumo}

O objetivo do trabalho foi identificar se o conhecimento produzido na área acadêmica está sendo utilizado pelos profissionais do judô. Além disso, foi verificada a integração dos profissionais do esporte judô com os profissionais da área da ciência do desporto. Dezessete técnicos de judô do estado de São Paulo responderam um questionário elaborado especificamente para este estudo, o qual foi validado por 4 professores universitários da área de atuação relacionada a lutas ou judô. Os resultados mostraram que a minoria destes técnicos possui a graduação em educação física. Os participantes têm preferência pelos conhecimentos específicos do judô em detrimento dos conhecimentos das áreas da ciência do desporto e acham que o profissional de educação física seria o profissional ideal para a interação no desenvolvimento de seus programas de treinamento.

\section{Palavras-Chaves}

Judô; Treinamento desportivo; Regulamentação da profissão.

\section{SCIENTIFIC PRODUCTION IN JUDÔ: FROM THE ACADEMY TO THE GYM.}

Luiz Henrique da Silva

Antônio Carlos Tavares Junior

Alexandre Janotta Drigo

\begin{abstract}
The objective of this work was to identify if the knowledge produced in the academic field is being utilized by judo professionals. Furthermore, the integration of judo sport professionals with the professionals of the sport science field was verified. Seventeen judo coaches of the São Paulo State answered a questionnaire elaborated specifically for this study, which was validated by four university professors of the field related to judo or fights. The results showed that the minority of these coaches have a physical education degree. The participants have preference for judo specific knowledge in detriment of the sport science field knowledge and think that the physical education professional would be the ideal professional for the interaction in the development of their training programs.
\end{abstract}

\section{Key-Words}

Judo; Sport training; Profession regulation.

CONEXÕES, revista da Faculdade de Educação Física da UNICAMP, Campinas, v. 6, ed. especial, p. 665-677, jul. 2008.665 ISSN: $1983-9030$. 


\section{INTRODUÇÃO}

O Judô é uma arte marcial e esporte olímpico que possui um grande número de praticantes federados no país, e vêm sendo apontado, pela mídia, como uma das grandes potências competitivas no cenário internacional. No último mundial de judô, realizado em 2007 na cidade do Rio de Janeiro, foram conquistadas 3 medalhas de ouro e uma de bronze (Fonte www.cbj.com.br). Apesar deste fato inédito para o judô brasileiro, pois até o presente momento apenas o judoca João Derly havia conquistado uma medalha de ouro em mundial, os métodos de treinamento ainda são regidos às margens do empirismo, visto o escasso número de publicações científicas existente com esta modalidade no Brasil (COSSOLINO et al., 2004).

O judô foi idealizado no Japão, e sua criação é atribuída a Jigoro Kano, que o construiu derivando dos vários estilos de Ju-Jitsu (DRIGO, 1999). Fazendo parte da categoria das lutas agarradas, o judô é constituído de técnicas de projeção, quedas, estrangulamentos, imobilizações e chaves de articulação (SILVA; PELLEGRINI, 2007). A Kodokan, primeira escola oficial de Judô, foi fundada em 1882, mas teve grande reconhecimento público entre 1886 e 1889 (SUZUKI, 1986). A introdução desta modalidade no Brasil ocorreu no início do século XX em decorrência de dois fatores: imigração japonesa e a vinda de Konde Koma. Na primeira, o judô era praticado em clãs isolados, pouco disseminando a modalidade, sendo que a prática era realizada nos mesmos moldes da sua origem na cultura oriental. Mitsuo Maeda, conhecido como Konde Koma, foi responsável por uma divulgação da luta, realizando desafios de vale tudo por toda a América. Fato importante, é que em nenhum momento foi designada pela Kodokan uma missão de divulgação e introdução da modalidade em nosso país (DRIGO, 1999). Este fato pode ter contribuído de forma significativa para que a modalidade ficasse restrita às adaptações quando introduzida em uma nova cultura, resistindo as modificações da ciência e aos modelos de práticas esportivas (DRIGO et al., 2005). Com argumentação de manutenção da cultura, as artes marciais lutam contra as mudanças na sua prática, mantendo modelos de treinamento arcaicos e inadequados (DRIGO et al., 2003). Desta maneira, o judô vive atualmente um conflito entre as novas práticas de treinamento desportivo voltadas para o rendimento, que seria altamente adequada na prática do judô competitivo, e o judô "tradicional", preso ás suas origens e métodos antigos de prática desportiva (DRIGO et al., 2006).

A mídia coloca o judô brasileiro num alto patamar em decorrência dos resultados olímpicos (DRIGO et al., 2006). Entretanto, esse esporte sofre com a escassez de investimentos, ficando quase que restrito à iniciativa pública, refletida pela bolsa atleta e Lei Piva (Fonte www.esporte.gov.br). A fala de Leandro

CONEXÕES, revista da Faculdade de Educação Física da UNICAMP, Campinas, v. 6, ed. especial, p. 665-677, jul. 2008.666 ISSN: $1983-9030$. 
Guilheiro, medalhista olímpico em Atenas 2004, reflete bem a situação do incentivo à modalidade - "Não consegui um patrocinador. Desde a Olimpíada não visto um quimono." (GARAVELLO, 2005). Apesar da mídia colocar o judô como um esporte de destaque olímpico e discursando sobre a evolução desta modalidade, Drigo et al. (2006) analisando a evolução qualitativa e quantitativa das medalhas olímpicas do judô brasileiro, chega a conclusão de que esta evolução não existiu, sendo apenas um produto do otimismo e falação realizada por dirigentes e programas televisivos esportivos.

Além do judô, Drigo et al. (2006) estende sua análise para a realidade do esporte individual olímpico brasileiro, comentando a modesta participação olímpica em esportes individuais a que se restringiu em Atenas 2004, com medalhas no iatismo, hipismo, judô e atletismo apenas. Apesar desta participação modesta, o discurso da mídia nos coloca num momento de evolução, encobertando a verdadeira realidade, dificultando ainda mais a busca para novas atitudes (DRIGO et al., 2006).

Este estudo foi desenvolvido com a necessidade da compreensão da verdadeira realidade da modalidade judô em nosso país. Precisamos sair da falação provocada pela mídia, assunto muito bem apresentado por DRIGO et al., (2006), e buscar fontes de informações científicas, as quais possam refletir o status quo do judô brasileiro. Dessa maneira, o objetivo do presente estudo foi identificar o quanto o conhecimento produzido na área acadêmica está sendo utilizado pelo campo profissional do judô, verificando o acesso a esses materiais acadêmicos relacionados ao treinamento esportivo (como psicologia, biomecânica, fisiologia, marketing esportivo e ao próprio judô) com o intuito de estruturarem treinamentos, organizarem eventos, atraírem investimentos e reciclarem seus conhecimentos. Além disso, analisamos a interdisciplinaridade da área, verificando a integração dos profissionais do esporte judô com os profissionais da área da ciência do desporto, fazendo um retrato da área profissional do judô frente a regulamentação da profissão educação física (Lei 9696/98).

\section{MÉTODO}

Para a coleta de dados, foi elaborado especificamente para este estudo um questionário com questões do tipo fechada. Para validação do instrumento, o questionário foi submetido às observações e críticas de 4 professores Universitários (Unesp -Rio Claro, FAM - Americana, Ufscar, UFRJ) da área de atuação relacionada a lutas ou judô. Participaram do trabalho 17 técnicos de Judô, em sua maioria da região de Rio Claro - SP.

CONEXÕES, revista da Faculdade de Educação Física da UNICAMP, Campinas, v. 6, ed. especial, p. 665-677, jul. 2008. 667 ISSN: $1983-9030$. 


\section{RESULTADOS E DISCUSSÃO}

Participaram da pesquisa 17 técnicos de judô. Com base nos resultados, verificamos que 58,8\% dos técnicos não possuem formação universitária e $41,2 \%$ possuem formação universitária. Dos que possuem formação universitária, apenas 29,4\% são profissionais de Educação Física e mais da metade (70,6\%) são formados em outra área.

Estes resultados mostram que a maioria dos técnicos entrevistados não possuem formação universitária, o que podemos relacionar como característica da ocupação, ou seja, sem uma comissão específica de ética e possibilidade de processo frente às entidades profissionais. Aparentemente essa grande maioria que não tem formação universitária encara o encargo de técnico de judô como profissão, o que nos leva a crer, que têm como obrigação profissional buscar e atualizar conhecimentos. Entretanto, menos de $30 \%$ são educadores físicos, portanto a grande minoria está, teoricamente, apta a lidar com atividade física.

Além do perfil da formação profissional dos técnicos, verificamos as categorias com as quais os técnicos desenvolvem o trabalho com o judô. A Figura 1, mostra que a maioria dos técnicos (82.3\%) atua em todas as categorias, tendo uma pequena porcentagem que atua somente na categoria adulta $(11,8 \%)$ ou nas categorias masculinas menores (5.9\%). Nenhum dos técnicos atua somente nas categorias femininas menores e adultas.

Os dados da Figura 1 relatam um trabalho generalista realizado pela maioria dos técnicos, lidando com todas as faixas etárias e atuando com ambos os sexos. Essa generalização é retrato da negação da especificidade e multidisciplinaridade que envolve o treinamento desportivo moderno. A falta de distinção e redefinição do trabalho com faixas etárias diferentes é um problema ainda muito observado nos costumes e tradições do Judô.

CONEXÕES, revista da Faculdade de Educação Física da UNICAMP, Campinas, v. 6, ed. especial, p. 665-677, jul. 2008. 668 ISSN: $1983-9030$. 


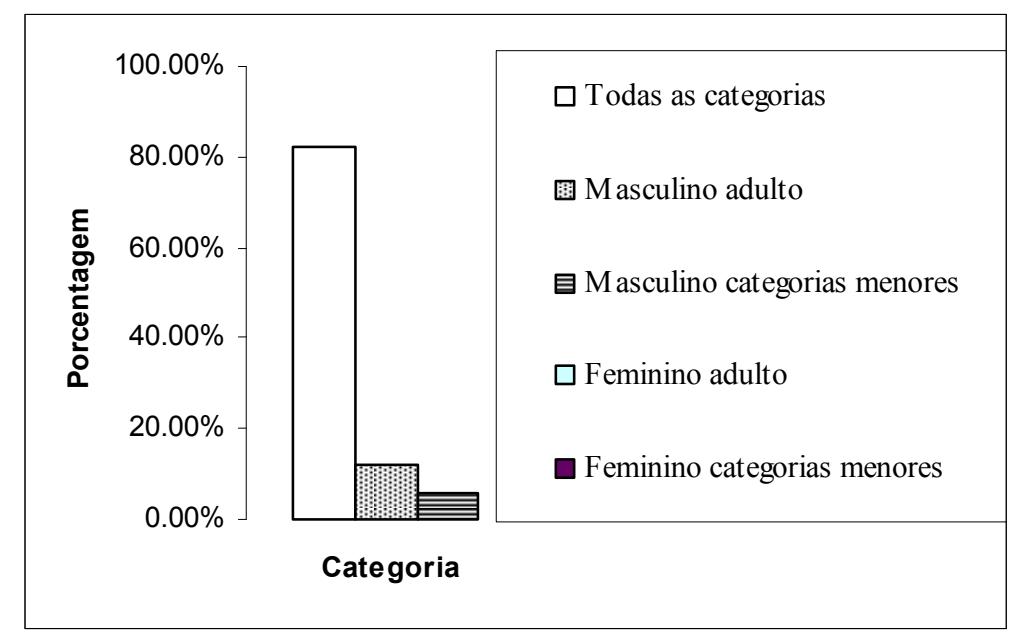

Figura 1- Relação dos técnicos, em porcentagem, com as categorias com as quais desenvolvem o treinamento de judô.

Também foi de nosso interesse investigar as áreas do conhecimento da ciência do esporte que esses técnicos consideram mais importante para o trabalho com Judô. A Tabela 1 nos mostra o resultado em ordem de grau de importância, ou seja, $1^{\circ}$ a área mais importante e $9^{\circ}$ a área de menor importância.

Quanto às áreas do conhecimento, os técnicos entrevistados, colocam a história, filosofia e ética do judô em primeiro plano, seguido das técnicas de judô e arbitragem de judô, aparecendo apenas no quinto posto teoria do treinamento desportivo e no último posto gestão de marketing desportivo. Isso nos leva a crer, que esses técnicos não possuem na sua grande maioria, atletas de maior expressão competitiva, pois não se preocupam ou consideram importantes algumas áreas indispensáveis para o sucesso competitivo.

Nota-se preferência pelos conhecimentos específicos do judô em detrimento a, por exemplo, teoria do treinamento desportivo, fisiologia e biomecânica. Essa posição dogmática reflete a importância dada aos “conhecimentos embutidos na faixa-preta ou graduação superior”, ou seja, para esses técnicos as outras áreas do conhecimento estão sempre atrás daquelas que estejam dentro do judô, refletindo o "poder místico" que envolvem esses conhecimentos e a tradição da modalidade.

CONEXÕES, revista da Faculdade de Educação Física da UNICAMP, Campinas, v. 6, ed. especial, p. 665-677, jul. 2008. 669 ISSN: $1983-9030$. 
Tabela 1 - Conhecimentos considerados mais importantes por técnicos para o trabalho com Judô.

\begin{tabular}{cl}
\hline Conhecimentos de História, Filosofia e Ética do Judô. & $1^{\mathrm{o}}$ \\
\hline Conhecimentos Técnicos de Judô (específico). & $2^{\mathrm{o}}$ \\
Arbitragem no Judô & $3^{\mathrm{o}}$ \\
Pedagogias do esporte & $4^{\mathrm{o}}$ \\
Fisiologia do esporte Teoria do treinamento desportivo & $5^{\mathrm{o}}$ \\
Psicologia do esporte & $6^{\mathrm{o}}$ \\
Biomecânica do esporte & $7^{\mathrm{o}}$ \\
Fisiologia do esporte & $8^{\mathrm{o}}$ \\
Gestão de marketing esportivo & $9^{\mathrm{o}}$ \\
\hline
\end{tabular}

Após identificarmos a ordem de importância das áreas do conhecimento da ciência do esporte para o desenvolvimento do trabalho com o judô, verificamos quais dessas áreas eram de domínio ou conhecimento dos técnicos. A Tabela 2 abaixo nos mostra em porcentagem a relação dos técnicos com o domínio da área de conhecimento. Além disso, a Tabela 2 apresenta a porcentagem dos técnicos que citaram alguma obra ou autor do respectivo assunto, dentre aqueles que afirmaram ter domínio ou conhecimento da área em questão.

\section{Tabela 2 - Áreas do conhecimento que os técnicos de Judô mais têm contato.}

\begin{tabular}{ccc}
\hline & $\begin{array}{c}\text { Afirmam buscar } \\
\text { Conhecimento }\end{array}$ & Citou obra ou autor \\
\hline Conhecimentos do Judô & $82,3 \%$ & $70,6 \%$ \\
Teoria do treinamento desportivo & $70,6 \%$ & $47 \%$ \\
Fisiologia do esporte & $64,7 \%$ & $53 \%$ \\
Psicologia do esporte & $58,9 \%$ & $35,3 \%$ \\
Pedagogia do esporte & $53 \%$ & $41,2 \%$ \\
Biomecânica do esporte & $41,2 \%$ & $35,3 \%$ \\
Gestão de marketing esportivo & $5,9 \%$ & $5,9 \%$ \\
\hline
\end{tabular}

Conforme apresentado na Tabela 2, a área em que os técnicos entrevistados afirmam mais buscar conhecimento é a técnica específica do judô, porém nem todos recordaram-se de obras ou autores referentes a esse tema. O segundo posto ficou com treinamento desportivo, porém menos da metade citaram obras ou autores, sendo que muitas dessas obras não tinham ligação direta com a área de conhecimento em questão, fato esse, que ocorreu também, com fisiologia, psicologia, biomecânica e pedagogia. Dessas obras citadas, a grande maioria se refere as apostilas ou cursos do CREF, apontando 
que essa população não tem algum contato com a literatura específica da ciência do desporto e a aproximação que possuem com a Educação Física é devido a Lei 9696/9.

Foi perguntado aos técnicos, quais cursos complementares seriam importantes para o desenvolvimento do trabalho com o judô. Nesta pergunta poderia ser anotada mais de uma resposta. Desta maneira, a soma dos resultados, que são apresentados em porcentagem, ultrapassa 100\%. A Figura 2 abaixo apresenta as respostas obtidas.

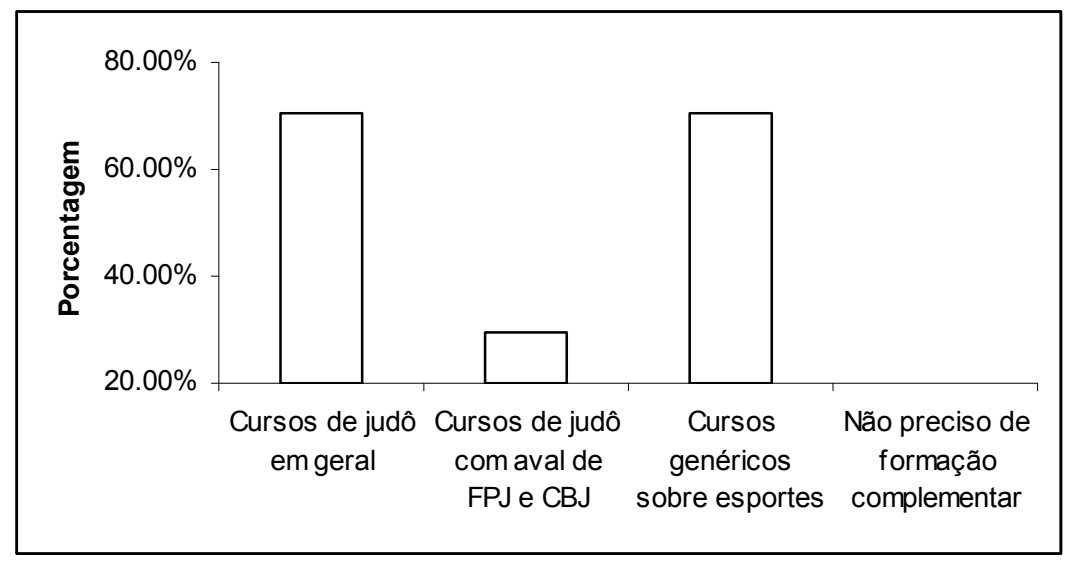

Figura 2- Cursos complementares considerados importantes para o desenvolvimento o trabalho como técnico de judô.

Após os técnicos responderem quais cursos eram importantes, buscamos identificar quais cursos eram freqüentados pelos mesmos. Os resultados mostraram que $82,3 \%$ dos técnicos afirmaram ter participado de cursos de formação complementar sobre uma das áreas de conhecimento destacadas no trabalho e 17,7\% não participaram de cursos de formação complementar. Dos 83,3\% que afirmaram participar de cursos, 71,4\% disseram ter participado de cursos promovidos pela Federação Paulista de Judô (FPJ) ou que tinham como tema específico o Judô e 28,6\% participaram de cursos com temas genéricos sobre esportes ou cursos promovidos por entidades acadêmicas. Além da participação em cursos, 5,9\% dos técnicos afirmaram ter ministrado algum tipo de curso promovido pela FPJ e 94,1\% dos técnicos não ministraram nenhum tipo de curso.

Como verificado nos resultados acima apresentados sobre os cursos de formação complementar, os técnicos entrevistados, na maioria, afirmaram ser importante a participação de cursos sobre judô, ministrados ou não pela FPJ, e igualmente de cursos genéricos que tenham esporte como temática. Todavia, não é bem isso o que ocorre pois $82,3 \%$ afirmam ter participado de cursos de formação CONEXÕES, revista da Faculdade de Educação Física da UNICAMP, Campinas, v. 6, ed. especial, p. 665-677, jul. 2008.671 ISSN: $1983-9030$. 
complementar, mas desse total, 71,4\% participaram de cursos promovidos pela FPJ que tinham como tema judô e somente $28,6 \%$ participaram de cursos científicos sobre esportes, promovidos por entidades

acadêmicas. Mais uma vez, fica claro que esses técnicos dão plena importância aos conhecimentos próprios do judô e deixam em segundo plano as áreas de conhecimento da ciência desportiva. Os resultados ficam mais alarmantes, quando observamos os resultados com relação aos cursos ministrados por esses técnicos. Apenas 5,9\% deles ministraram algum tipo de curso, sendo que os mesmos foram promovidos pela FPJ. Nenhum técnico ministrou algum curso com caráter acadêmico, o que retrata a distância entre esses senhores e a ciência desportiva.

Além da busca de cursos complementares, foi investigado o interesse na interação com outros profissionais para a formação da comissão técnica. Diante deste questionamento, obtemos que 70,6\% dos técnicos acham que a interação com outros profissionais é importante, basta que sejam competentes. Os outros 29,4\% dos técnicos acham que a interação é importante, desde que tais profissionais sejam judocas. Nenhum técnico mencionou que a interação com outros profissionais atrapalharia o treinamento ou que o conhecimento obtido até a faixa-preta fosse o suficiente para o trabalho com judô, não necessitando de interação com outros profissionais. Dentro desta mesma temática, foi perguntado aos técnicos quais profissionais seriam escolhidos por eles para interagir no desenvolvimento do treinamento de seus atletas. A Tabela 3 apresenta os profissionais em ordem de importância (1 profissional de maior importância e 7 profissional de menor importância) que os técnicos buscariam interação para o desenvolvimento do seu trabalho com judô.

Estes resultados mostram que apesar das inúmeras manifestações das várias federações e adeptos das artes marciais contra o sistema do Conselho Federal de Educação Física (CONFEF), os técnicos participantes no presente estudo reconhecem a importância do profissional de Educação Física na preparação e estruturação de treinamentos, mostrando-se, na grande maioria, favoráveis a interação profissional. Verificou-se que para a interação com o judô, o educador físico é aquele que detém a preferência, mesmo para aqueles que relutam esse caráter multidisciplinar, se ocorresse essa interação, o educador físico é o profissional reconhecido como mais gabaritado para tal.

CONEXÕES, revista da Faculdade de Educação Física da UNICAMP, Campinas, v. 6, ed. especial, p. 665-677, jul. 2008.672 ISSN: $1983-9030$. 
Tabela 3 - Profissionais considerados mais importantes para interação com trabalho de Judô.

\begin{tabular}{cl}
\hline Profissionais de Educação Física & $1^{\circ}$ \\
\hline Médicos & $2^{\mathrm{o}}$ \\
Psicólogos & $3^{\circ}$ \\
Fisioterapeutas & $4^{\mathrm{o}}$ \\
Fisiologistas & $5^{\mathrm{o}}$ \\
Pedagogos do Esporte & $6^{\mathrm{o}}$ \\
Especialistas em Marketing Esportivo & $7^{\mathrm{o}}$ \\
\hline
\end{tabular}

\section{CONCLUSÃO}

A conclusão deste trabalho permitiu um importante mapeamento do perfil dos técnicos de judô no estado de São Paulo e as áreas de conhecimento consideradas importantes par ao desenvolvimento desta função. Além disso, foi realizada importante reflexão a cerca da utilização das produções acadêmicas no desenvolvimento dos treinamentos dos atletas de judô do estado e as possíveis interações com outros profissionais da área desportiva com o intuito da busca de novos conhecimentos para a excelência do treinamento. Dentro deste contexto e das especificidades do protocolo experimental do presente estudo, chegamos às seguintes conclusões:

- São poucos os técnicos que possuem graduação em educação física na atuação desta função;

- Em sua maioria, os técnicos de judô desenvolvem programas de treinamento para atletas de diferentes faixas etárias, gêneros e graduações no judô. Uma pequena porcentagem dos técnicos trabalha de forma especializada numa determinada população de atletas.

- Há uma preferência pelos técnicos entrevistados no presente estudo pelos conhecimentos específicos do judô em detrimento dos conhecimentos das áreas da ciência do desporto, treinamento, biomecânica e fisiologia, por exemplo. Refletindo a importância dada aos "conhecimentos embutidos na faixa-preta ou graduação superior". Poucos trabalhos acadêmicos foram citados pelos técnicos como fonte de informação e atualização, sendo que o pouco conhecimento científico relacionado à ciência do esporte que buscam em sua formação 
complementar é norteado, na maioria das vezes, pelo "senso comum" e empirismo, mesmo sendo os técnicos favoráveis a interação com outros profissionais. A ciência desportiva ainda não chega

- efetivamente aos seios do judô, mesmo que os contatos com essa possam existir de modos superficiais, como nos cursos do CREF.

- Os técnicos entrevistados afirmaram que realizam cursos de formação complementar. Entretanto, poucos técnicos fazem cursos promovidos por entidades acadêmicas que tratam de assuntos relacionados à ciência do desporto, limitando-se aos cursos da FPJ e, muitas vezes, freqüentando cursos caso o palestrante seja um judoca.

- O profissional de Educação Física tem sua importância reconhecida pelos técnicos de judô do presente estudo. Entretanto, reflete-se que essa interação deve ocorrer de forma mais efetiva tendo em vista as necessidades básicas para a área do judô, como treinamento mais adequado em relação aos conhecimentos oriundos da Ciência do Desporto e o aumento das pesquisas em judô no campo acadêmico brasileiro.

\section{REFERÊNCIA}

BRASIL.Ministério dos Esportes. Lei 9696/98. Disponível em: <http://www.esportes.gov.br>. Acesso em 1. nov. 2007.

COSSOLINO, C. L. et al. Perspectivas da produção científicas nas artes marciais. In: II SepefSEMINÁRIO DE ESTUDOS E PESQUISAS EM FORMAÇÃO PROFISSIONAL NO CAMPO DA EDUCAÇÃO FÍSICA, 2. 2004, Rio Claro. A formação profissional no campo da educação fisica: limites e possibilidades., 2004. v. 2. p. 41-41.

DRIGO, A. J. História do judô no Brasil: A contribuição dos senseis uadi mubarac ( $8^{\circ}$ Dan) $36 \mathrm{f}$. Monografia (Trabalho de Conclusão de Curso de Bacharel em Educação Física) - Instituto de Biociências, Universidade Estadual Paulista, Rio Claro, 1999.

. ; OLIVEIRA, P. R. ; CESANA, J. O judô brasileiro, o desempenho, e as mídias: caso das Olimpíadas de Atenas 2004 e o mundial do Cairo de 2005. Conexões, Campinas, v. 4, n. 1, p. 4, 2006.

CONEXÕES, revista da Faculdade de Educação Física da UNICAMP, Campinas, v. 6, ed. especial, p. 665-677, jul. 2008. 674 ISSN: $1983-9030$. 
DRIGO, A. J. et al. A cultura oriental e o processo de especialização precoce nas artes marciais. Lecturas Educacion Fisica y Deportes, Buenos Aires, v. 86, 2005.

DRIGO, A. J. et al. A Educação Física e as Artes Marciais. Revista CREF4/SP - p. 25 - 26, dez. 2003.

GARAVELlO, M. Medalha olímpica gera frutos distintos para judocas. Cadernos de Esportes. Disponível em: <http://www.uol.com.br>. Acesso em: 24 fev. 2005.

CONFEDERAÇÃO Brasileira de Judô. Disponível em: <http://www.cbj.com.br>. Acesso em: 1 de Nov. 2007.

SILVA, L. H. ; PELLEGRINI, A. M. A contribuição do judô para a qualidade de vida: as quedas. Revista FAFIBE Online, v. 3, p. 104, 2007.

SUZUKI, E. O pai da educação integral e o universo do Judô. São Paulo: Ed. do Escritor, 1986. 


\section{Luiz Henrique da Silva}

FAFIBE - Bebedouro/SP

UNIVAS - Pouso Alegre/ MG

Avenida 2A - n.868 Bairro Bela Vista

Rio Claro - SP CEP: 13506-780

e-mail: lhsilva@rc.unesp.br

FONE: (19) 3523 - 8361 ou (19) 81399795

\section{Antônio Carlos Tavares Junior \\ UNESP - Rio Claro/SP}

\section{Alexandre Janotta Drigo}

Faculdade de Educação Física/Unicamp

Referência do artigo:

\section{ABNT}

SILVA, L. H. ; TAVARES JUNIOR A. C.; DRIGO, A. J. PRODUÇÃO CIENTíFICA NO JUDÔ: DA ACADEMIA ÀS ACADEMIAS. Conexões, v. 6, ed. especial, p. 665-676, 2008.

\section{APA}

SILVA, L. H. ; TAVARES JUNIOR A. C., \& DRIGO, A. J. (2008) PRODUÇÃO CIENTÍFICA NO JUDÔ: DA ACADEMIA ÀS ACADEMIAS. Conexões, 6(ed. especial), 665-676.

\section{VANCOUVER}

SILVA LH, TAVARES JUNIOR AC, DRIGO A. J. PRODUÇÃO CIENTÍFICA NO JUDÔ: DA ACADEMIA ÀS ACADEMIAS. Conexões, 2008; 6(ed. especial): 665-676. 
